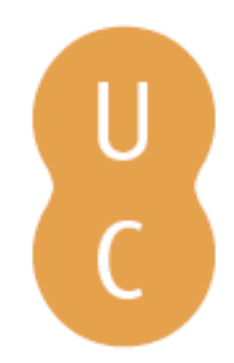

\title{
pompalina
}

\section{A festa de Santo Antônio dos lusobrasileiros: religiosidade, comida e lazer}

Autor(es): Rocha, Ariza Maria

Publicado por: Imprensa da Universidade de Coimbra

URL

persistente: URI:http://hdl.handle.net/10316.2/45238

DOI: $\quad$ DOI:https://doi.org/10.14195/978-989-26-1721-3_11

Accessed : $\quad$ 26-Apr-2023 12:48:27

A navegação consulta e descarregamento dos títulos inseridos nas Bibliotecas Digitais UC Digitalis, UC Pombalina e UC Impactum, pressupõem a aceitação plena e sem reservas dos Termos e Condições de Uso destas Bibliotecas Digitais, disponíveis em https://digitalis.uc.pt/pt-pt/termos.

Conforme exposto nos referidos Termos e Condições de Uso, o descarregamento de títulos de acesso restrito requer uma licença válida de autorização devendo o utilizador aceder ao(s) documento(s) a partir de um endereço de IP da instituição detentora da supramencionada licença.

Ao utilizador é apenas permitido o descarregamento para uso pessoal, pelo que o emprego do(s) título(s) descarregado(s) para outro fim, designadamente comercial, carece de autorização do respetivo autor ou editor da obra.

Na medida em que todas as obras da UC Digitalis se encontram protegidas pelo Código do Direito de Autor e Direitos Conexos e demais legislação aplicável, toda a cópia, parcial ou total, deste documento, nos casos em que é legalmente admitida, deverá conter ou fazer-se acompanhar por este aviso.

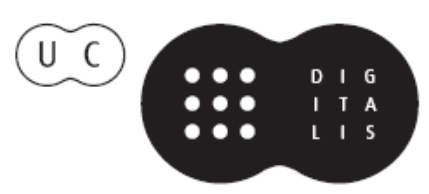


Carmen Soares

Gilene da Silva Gomes Ribeiro

(coords.)

\section{Mesas \\ LUSO-BRASILEIRAS}

\section{ALIMENTAÇÃO, SAÚdE \& GULTURA}

\section{VOLUME I}

IMPRENSA DA UNIVERSIDADE DE COIMBRA COIMBRA UNIVERSITY PRESS

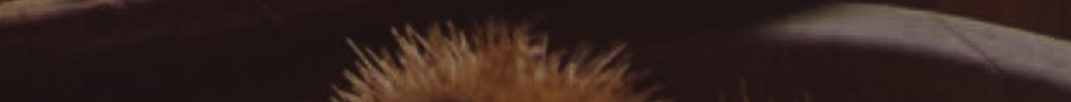




\title{
A festa de Santo Antônio dos luso- BRASILEIROS: RELIGIOSIDADE, COMIDA E LAZER
}

\author{
(The luso-brazilians' feast of Saint Anthony: \\ religiosity, food and leisure)
}

\author{
Ariza Maria Rocha \\ Universidade Regional do Cariri (URCA) \\ (arizarocha2000@yahoo.com.br)
}

Resumo: A herança dos portugueses enraizou-se na formação cultural dos brasileiros. Este trabalho enfoca a religião, com destaque para a festa religiosa a Santo Antônio de Lisboa (ou Santo Antônio de Pádua). Tal influência foi trazida pelos franciscanos que acompanhavam os navegantes pioneiros e proliferou-se nos domínios portugueses. Dada a fama de ser o santo "casamenteiro", "milagreiro" e protetor dos pobres, seu culto incorporou-se na cultura e na devoção luso-brasileira e persiste até hoje. As homenagens ao santo são realizadas no dia 13 de junho em ambos os países, com festas tradicionais que guardam aproximações e distanciamentos culturais, tanto na parte da comida como nos espaços de lazer e socialização criados nas festas lisboetas e do nordeste brasileiro. Esta comunicação objetiva identificar, a partir da festa religiosa de Santo Antônio, as aproximações e os distanciamentos da cultura portuguesa (Lisboa) e brasileira (Barbalha) quanto às comidas e bebidas típicas do local e do lazer como forma de manifestação popular e como valor imaterial que apresenta benefícios de bem-estar aos participantes dos citados países. Para a investigação desse patrimônio alimentar, foram utilizados um estudo comparativo e documentos, tais como iconografias e jornais, além de recorrer as fontes hagiográficas do santo paduano.

Palavras-chave: festa, Santo Antônio Luso-Brasileiro, religiosidade, comida, lazer.

Авstract: The Portuguese heritage took root in the cultural formation of the Brazilian people. This work focuses on religion and highlights Saint Anthony of Lisbon's religious feast (or Saint Anthony of Padua). Such influence was brought by the Franciscans, who accompanied the pioneer navigators, and proliferated across the Portuguese domains. Due to his reputation of "matchmaker", "miracle worker" and protector of the poor, his worship has been incorporated into the Luso-Brazilian culture and this devotion persists until nowadays. His feast day is on the $13^{\text {th }}$ of June in both countries and comprises traditional festivals characterized by cultural proximities and distances concerning the food as well as the leisure and socializing spaces created in Lisbon and in the Brazilian Northeast. This communication aims 
to identify, taking Saint Anthony's religious festivities as the start point, the approaches and distances between the Portuguese culture (Lisbon) and the Brazilian culture (Barbalha) as to typical local food and drinks, as well as leisure as a means of popular expression and immaterial value that brings wellness to the participants of the previously mentioned countries. In order to investigate this food heritage, a comparative study was carried out encompassing the analysis of documents such as, iconography and newspapers, as well as the Paduan saint's hagiographical sources. KEYWords: feast, Luso-Brazilian Saint Anthony, religiosity, food, leisure.

Algumas comidas estão relacionadas a determinadas festas. Apesar de muitas das tradições alimentares renovarem-se com o tempo, a bênção do pão, o mungunzá e a cachaça são elementos associados às festas de Santo Antônio em Barbalha, município do Estado do Ceará (CE), no Brasil; enquanto o "pão de Santo Antônio", a sardinha e a sangria ainda fazem parte da festa em Lisboa, em Portugal. Esta comunicação tem o objetivo de analisar as referidas comidas e bebidas no lazer da festa de Santo Antônio, realizada no dia 13 de junho, em Lisboa (Portugal) e em Barbalha (Brasil).

Para tanto, partimos do princípio de que tais práticas alimentares criam espaços e momentos de sociabilidade pelo compartilhamento à mesa, ou seja, afloram o prazer de dividir "o de comer e o de beber" com o outro nos momentos sagrados e populares da referida festa. Por esse prisma, a comida revela o ritual e a identidade cultural, bem como os aspectos de continuidade e ruptura cultural entre os dois países.

A abordagem por nós adotada é a histórico-cultural da alimentação, com a utilização da pesquisa bibliográfica e documental, a exemplo da fonte hagiográfica ${ }^{1}$. Adotaremos o conceito de lazer de Elias e Dunning ${ }^{2}$, no contexto da teoria do processo civilizador.

No pensamento dos autores supracitados, o lazer emerge como possibilidade de externar as emoções e de produzir experiências agradáveis e prazerosas para além das obrigações rotineiras das sociedades industrializadas. Nesse enfoque, o lazer é constituído pelos seguintes elementos: trabalho privado e administração familiar, repouso, provimento das necessidades biológicas, sociabilidade e atividades miméticas ou de jogo. Restringimo-nos à sociabilidade, que "[...] significa dizer que um elemento do prazer é o sentimento agradável vivido pelo facto de se estar na companhia dos outros sem qualquer obrigação ou dever para com eles"3. Entre as muitas atividades que pertencem ao quadro, os autores citam a comida compartilhada com o outro.

\footnotetext{
1 Quaracchi 2012.

Elias \& Duning 1992.

Elias \& Duning 1992: 179.
} 
Após essas explicações iniciais, explanaremos a temática pelo seguinte roteiro: inicialmente, abordaremos os passos da vida do santo português e a devoção trazida pelos frades franciscanos ao Brasil, em particular à cidade de Barbalha, localizada ao sul do estado do Ceará. Em seguida, trataremos a respeito da comida e da bebida no lazer da festa que homenageia o santo na capital portuguesa e na cidade cearense. A comida nos permite fazer um paralelo do lazer sagrado e profano, bem como entre as aproximações e os distanciamentos entre os dois países aqui em tablado.

\section{i. Das trilhas do homem-Santo paduano de Lisboa À devoção BARBALHENSE}

Santo Antônio tem a fama de ser santo casamenteiro, ressuscitar os mortos, curar as enfermidades, encontrar objetos e pessoas perdidas, proteger os pobres e combater as heresias. Por esses e outros fatos e milagres, seu culto incorporou-se na cultura e na devoção luso-brasileira e persiste até os dias atuais.

Reconhecido por Pio XII em 1946 como o Doutor Evangélico, quando jovem, o então Fernando Martins de Bulhões e Taveira, filho de nobres, renunciou à vida mundana e ao conforto material para dedicar-se à vida evangélica regada de oração, estudos teológicos, trabalho apostólico e clausuro. Abraçando a pobreza, abrindo mão de bens materiais e entregando-se ao mundo espiritual, Santo Antônio notabilizou-se como taumaturgo, orador e defensor dos necessitados.

Santo Antônio de Lisboa, ou de Pádua, recebeu a auréola da santidade pelo Papa Gregório IX no ano de 1232, após alguns meses de seu falecimento, em 1231, tamanha era a popularidade de suas obras, sermões e milagres que compuseram o cenário do século XII na luta contra o mundo muçulmano.

Contudo, apesar de ser considerado o santo mais popular no mundo, ainda há muitas dúvidas nas fontes hagiográficas em relação à data do nascimento e de outros aspectos de sua vida, o que se reflete, por conseguinte, na dificuldade de se calcular a idade ${ }^{4}$ do santo na ocasião de seu óbito, no dia 13 de junho, em Arcella, próximo de Pádua, na Itália. Essa data foi escolhida para celebrar a vida do santo e sua obra. Assim, as festas religiosas têm o caráter de preservação da imagem e do exemplo do santo, ou seja, "[...] não significam apenas a comemoração de um acontecimento, mas a sua reatualização, uma forma de reviver o tempo original e promover a purificação" 5 .

\footnotetext{
${ }^{4}$ Há, também, divergência da idade com que faleceu o santo. Algumas fontes, como Braga 2012, mencionam que a vida do santo terminou aos 36 anos. Já Lopes afirma que “[...] o Santo quando morreu era um homem já caduco, a entrar numa velhice acentuada pelos cansaços do muito que trabalhara”. Lopes 1992: 280.

5 Couto 2008: 2.
} 
A respeito das fontes hagiográficas, Santos e Duarte ${ }^{6}$ explicam que elas são importantes para que os(as) santos(as) não caiam, com o tempo, no esquecimento (esse papel de memória é levado a cabo pela Igreja) e, consequentemente, para que os devotos continuem tendo o(a) santo(a) como exemplo a ser seguido e assistência diante dos apelos e orações. Nessa linha de raciocínio, esses momentos festivos contribuem para a edificação dos fiéis da manutenção das tradições fundamentadas na hierarquia social da Igreja e para a inclusão das camadas populares nessas festividades visando à evangelização.

Os milagres de Santo Antônio foram inicialmente divulgados em Lisboa, sendo conhecidos posteriormente em Coimbra, Pádua e mundo afora, como, por exemplo, na América Portuguesa. Assim, a inserção da devoção de Santo Antônio no Brasil ocorreu pelas vias religiosa/educacional, militar e cultural. Por muitos caminhos, a fé e a festa ao santo português e de Pádua floresceram em terras brasileiras que seguia o modelo português ${ }^{7}$, e de Lisboa à Barbalha do Ceará, dois países unem-se para comemorar à fé no Santo Antônio:

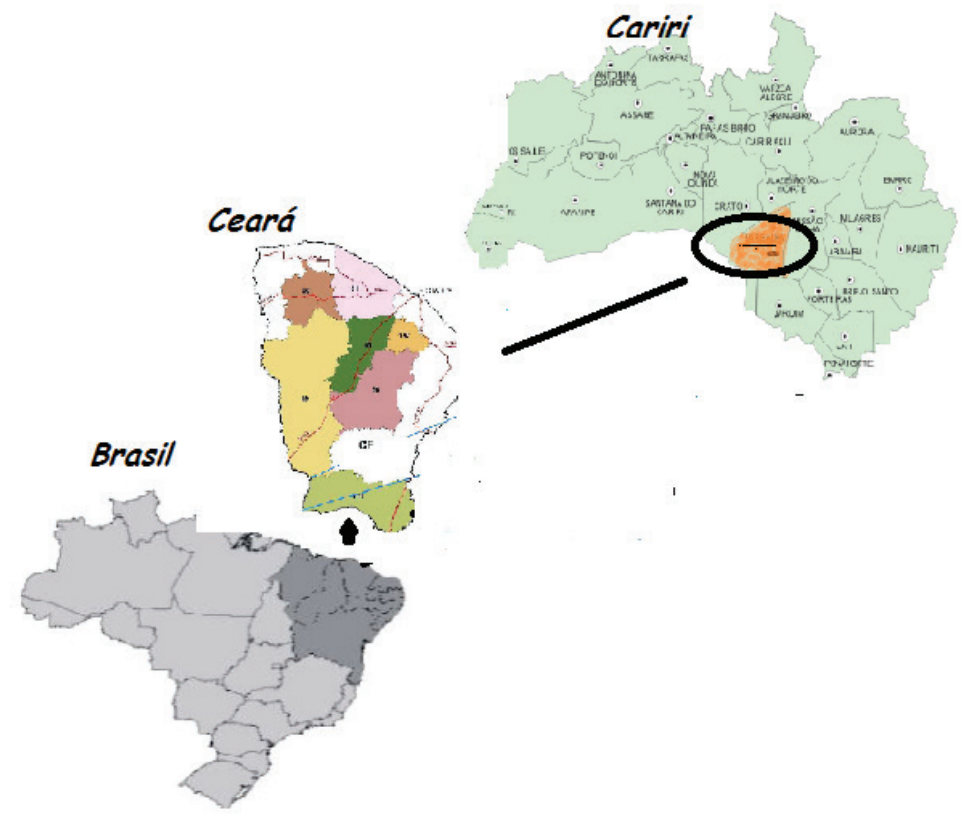

Figura 1: Localização de Barbalha

Fonte: Adaptação de BRASIL, 2010.

\footnotetext{
${ }^{6}$ Santos \& Duarte 2010.

7 Sobre o assunto consultar Jancsó e Kantor 2001.
} 


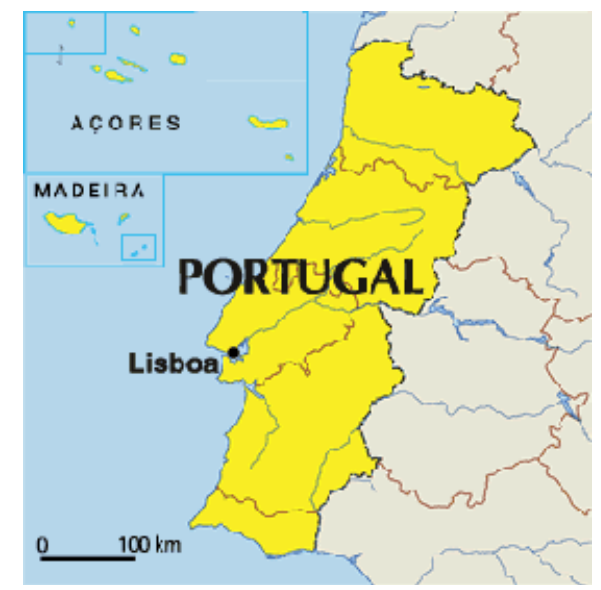

Figura 2: Localização de Lisboa

Fonte: EUROPEAN UNION, 2017.

Semelhante ao que ocorreu em muitas regiões brasileiras, a devoção a Santo Antônio não ficou indiferente à cidade de Barbalha, no Ceará, que teve sua história e desenvolvimento econômico atrelados à religiosidade do povo principiados por volta do século XVII.

Em meados do século oitocentista, o Capitão Francisco Magalhães Barreto Sá, descendente de Mem de á $^{8}$, construiu em sua propriedade uma capela destinada a Santo Antônio, em torno da qual se ergueram as casas do arraial, que, posteriormente, foi elevado a Freguesia do Santo Antônio pela Lei Provincial n. ${ }^{\circ}$ 130, de 30 de agosto de 1838, e, anos depois, à categoria de cidade, com a denominação de Barbalha (Lei Provincial n. ${ }^{\circ} 1.740$, de 30 de agosto de 1876). O município desenvolveu-se sob a égide do santo lisboeta.

Barbalha cresceu e atualmente estima-se que tenha uma população de $58.347^{9}$ habitantes em uma área de $479,184 \mathrm{~km}^{2}$. Localizada ao sul do Estado do Ceará, faz fronteira com Crato, Juazeiro do Norte, Jardim e Missão Velha, compondo a Região do Cariri.

No percurso espacial e temporal, a devoção à figura do homem santo paduano de Lisboa cria raízes para além-mar, em particular, Barbalha. Em torno dessa imagem, está a Igreja relembrando e evangelizando os passos da santidade, seja pela forma sagrada, através das missas, procissões, cortejos,

8 Administrador português do Brasil colonial e terceiro Governador-Geral do Brasil no período de 1558-1572.

${ }_{9}$ IBGE 2014. 
rezas, bênçãos etc., seja pela dimensão popular, através das músicas, danças e comidas atribuídas ao santo.

Anualmente, a cidade de Barbalha transforma-se para festejar o padroeiro no dia 13 de junho, momento que representa uma respeitável data no calendário religioso e cultural caririense. A fama da tradicional festa tem repercutido no Ceará e está em estudo o seu tombamento como Patrimônio Imaterial pelo Instituto do Patrimônio Histórico e Artístico Nacional (Iphan).

Nesse palco de memória da vida do santo e da Igreja, trava-se a negociação entre as constâncias e permanências na dimensão sagrada e profana da festa de Santo Antônio, na qual a comida tem um importante papel no lazer e nos laços de continuidade e ruptura cultural entre os dois países aqui tratados, como veremos a seguir.

\section{Comidas e bebidas sagradas e profanas na festa de Santo Antônio: aproximações e distanciamentos do lazer luso- BRASILEIRO}

A comida particulariza o lugar, a ocasião, a condição financeira, a época do ano e o calendário litúrgico. Nessa direção, enfocaremos a festa de Santo Antônio, tanto no momento sagrado quanto no popular, realizada no mês de junho em Lisboa e em Barbalha, e as comidas e as bebidas associadas ao mencionado momento festivo.

$\mathrm{Na}$ condição de elemento básico e complexo da transformação da natureza em cultura, a comida extrapola o plano biológico e revela relacionamentos, sentimentos, ritos e procedimentos do homem com ele próprio, mas também com o outro, o divino e a natureza. Heck confirma-nos isso ao dizer que "[...] a comida deve ser tratada como um código, e as mensagens que codifica são encontradas na expressão das relações sociais" ${ }^{10}$.

Partindo da comida como um indicador social a ser desvendado, podemos nos aproximar dos identificadores alimentares da festa de Santo Antônio em Barbalha e Lisboa na condição de espaço de sociabilidade, no sentido empregado por Elias e Dunning, como elemento do lazer em que os comensais partilham a comida e as relações sociais, pois, como afirma Moreira, a “[...] sociabilidade faz parte da comida compartilhada" ${ }^{11}$ e não há celebração sem banquete. Por mais simples que seja, a comida comunga, integra, aproxima e "[...] apresenta-se como elemento decisivo da identidade humana e como um dos mais eficazes instrumentos para comunicá-la” ${ }^{12}$.

\footnotetext{
${ }_{10}$ Heck 2004: 139.

11 Moreira 2010: 23.

12 Montanari 2008: 16.
} 
A festa de Santo Antônio, em ambos os países, é dividida em duas faces: a sagrada e a profana. De um lado, a reverência nas missas, cânticos, procissões, cortejos, novenas, orações, comidas e bebidas abençoadas; do outro lado, o prazer da carne está nas ruas próximas, com quermesses, espetáculos, ornamentações, danças, músicas típicas, jogos, brincadeiras com o santo, comidas e bebidas tradicionais. As faces complementam-se e representam a ligação e/ou religação com o mundo espiritual e a entidade católica, como também apreende os laços entre religião, comida e lazer. Nas palavras de Del Priore, "É como se dentro de cada festa religiosa existisse uma profana e vice-versa"13.

É importante salientar que, apesar de cada festa ser um acontecimento exclusivo, há uma dinâmica própria da cultura que não é fixa e nem rígida, mas, por ser um processo longo, a festa passa por transformações, ora incluindo, ora excluindo componentes da tradição, os quais descreveremos nas próximas linhas.

Iniciaremos pela proteção do santo às cidades mencionadas. Santo Antônio é padroeiro de Barbalha desde o berço da criação da cidade. Já em Lisboa, o santo foi decretado padroeiro da cidade no ano de 1934, dividindo o referido título com São Vicente. Todavia, ressaltamos que, para além de Lisboa e de Barbalha, a proteção do patrono estende-se a outras cidades, como: Caieiras (São Paulo), Campo Grande (Mato Grosso), Duque de Caxias (Rio de Janeiro), Governador Valadares (Minas Gerais), Nova Iguaçu (Rio de Janeiro), Patos (Minas Gerais), Três Lagoas (Mato Grosso) etc.

As festas sagradas seguem as disposições da Igreja Católica na história desses países. Assim, tanto em Lisboa quanto em Barbalha, ocorrem missas de abertura e de encerramento, procissões, orações, novenas, cânticos, cortejos do santo e cultos à imagem. Em Lisboa, a liturgia começa com a realização da trezena realizada de $1 .^{\circ}$ a 12 de junho. No dia 13 , devotos chegam cedo à Igreja e acendem velas no pátio. Ao meio-dia, realiza-se a missa solene de abertura no Santuário-Casa de Santo Antônio à Sé. Para isso, enfeita-se o altar-mor com flores e com a imagem do santo em um painel de ambão ${ }^{14}$.

No horário da procissão, às 17 horas, inicia-se o cortejo processional, quando a estátua do santo é conduzida no andor, percorrendo as ruas em redor da Sé. A procissão é preparada pelas irmãs franciscanas e pelos bombeiros, que acompanham a segurança da procissão. À frente do cortejo, estão os acólitos. Logo atrás da imagem do santo, seguem a banda e as pessoas acompanhando os cânticos liderados pelo coro litúrgico. Por onde a imagem passa, as pessoas aplaudem e jogam flores. Após o percurso pelas ruas de Alfama, a procissão é

${ }_{13}$ Del Priore 2000: 19.

14 Suporte de madeira com o painel ou quadro de Santo Antônio no altar e destinado à leitura da epístola ou ao canto do evangelho. 
finalizada na Sé de Lisboa, momento da mensagem e hino de Ação de Graça. Em seguida, a imagem de Santo Antônio é transportada ao interior da Igreja e, à noite, às 8 horas, é realizada a missa de encerramento.

Em Barbalha, a festa também é precedida pela trezena e, durante cada noite, há um coordenador da celebração, denominado de noitário, que é responsável por transportar o andor do santo. $\mathrm{Na}$ missa solene de abertura, os devotos comparecem para homenagear e renovar sua fé, e entre eles estão os emissários dos grupos folclóricos da região. No momento da oferenda, os produtos regionais e a bandeira de Santo Antônio são abençoados. No dia 13, ocorre a procissão, quando o andor sai da Matriz e percorre as principais ruas da cidade. O público acompanha a procissão com cânticos, orações, velas e culto à imagem do santo. No final, há a missa solene de encerramento.

No contexto da festa sagrada, estão a comida e a bebida abençoadas, ou seja, o pão e o vinho, que fazem parte dos Sacramentos da Eucaristia. Para além dessa ocasião, tanto em Lisboa quanto em Barbalha, no dia 13, há a prática da bênção e a distribuição dos pães de Santo Antônio aos carentes, apesar de algumas famílias manterem a tradição de preservá-los em depósitos de abastecimentos na garantia de que nunca lhes falte comida em seus lares, isto é, a comida tem o poder de "[...] representa[r] coisas diferentes em momentos diferentes para pessoas diferentes" 15 .

Tal prática faz parte do exemplo vivo de humildade e de caridade da vida do santo; no entanto, não há uma única versão para o surgimento da bênção e da distribuição dos pães. A esse respeito, $\mathrm{Braga}^{16}$ conta que a prática surgiu na França devido à dificuldade que havia para se encontrar uma comerciante de pão. Com a intercessão do santo, a padeira conseguiu abrir seu estabelecimento e doou os pães aos carentes no dia 13 de junho, em nome do taumaturgo. Já a irmã franciscana da Ordem Franciscana Secular Santo Antônio de Lisboa ${ }^{17}$ (2012) conta:

[...] Frei António vivia, já famoso pelas suas pregações e caridade, no humilde conventinho de Santa Maria Mater Domini, em Pádua. Um dia, como já era costume naquela época, penosa pela pobreza, veio bater à porta do convento um pobrezinho pedindo algo para comer. Quem o atendeu foi Frei António, que, indo à despensa, pegou no pão - alimento tão precioso naquela época, sem dúvida mais do que hoje - preparado pelo frade cozinheiro e padeiro com tanto carinho. Não foi o único pobre atendido, nem o único pão dispensado por Frei António. Facto foi que a caixa do pão, pouco antes da refeição dos frades, ficou vazia e qual não foi o desapontamento e quase impaciência do frade

\footnotetext{
15 Pollan 2014: 28.

16 Braga 2011.

17 Monteiro 2012.
} 
cozinheiro quando, pouco tempo antes da refeição, se encontrou diante do facto consumado da falta de pão para a refeição dos co-irmãos que já se estavam dirigindo à capela para a oração. Encontrando-se com Frei António, o frade cozinheiro manifestou-lhe a situação crítica em que se encontravam ele e seus confrades, quase na hora da refeição. Diz-se que Santo António, sorrindo, lhe bateu nas costas dizendo: "Não se preocupe, irmão! Deus há-de providenciar!” De facto, ao voltarem os frades da oração para o refeitório, a caixa estava cheia de pães, causando surpresa ao frade cozinheiro!

Apesar de várias versões para a explicação do uso do pão, salientamos que se trata de um alimento que teve, no decorrer da história da humanidade $^{18}$, muitos significados simbólicos, sejam religiosos ou imaginários, em que o compartilhamento do pão "[...] reforçava os laços entre os convivas, permitindo o estabelecimento e a manutenção das relações sociais" ${ }^{19}$. E mais: “[...] significa a própria amizade, e também confiança, prazer e gratidão pela partilha"20.

Segundo a Igreja Católica, o pão e o vinho são o corpo e o sangue de Cristo, propiciando a aliança com os outros e com Deus, ou seja, é a transformação. Tal gesto tornou-se ritual nas missas e representa a carne (o pão) e o sangue (vinho) de Jesus Cristo, como memória da doação de sua vida. Eis o mistério da fé: a transformação da carne e do sangue em pão e vinho, como também a modificação da comida e da bebida, alimentos que, segundo Rodrigues, são os únicos:

[...] que a Igreja Católica Apostólica Romana olhou e considerou como dignos de, quando da celebração da Eucaristia, se transubstanciarem no corpo e no sangue de Jesus Cristo, o Redentor. Pois só eles - ao prover matéria e espírito, corpo e alma - alimentariam a "pessoa humana" na sua totalidade. Tal desdobramento, bem vincado no seio da Cristandade, acusava o toque mediterrâneo das suas origens e, ao mesmo tempo, o processo de evangelização de um preexistente legado, sobretudo, greco-romano ${ }^{21}$.

Nesse sentido, o pão e o vinho são considerados os alimentos da alma e do corpo no ritual religioso. $\mathrm{Na}$ sequência, apresentamos ilustrações da bênção e distribuição dos pães em Barbalha e Lisboa:

\footnotetext{
18 Para maiores informações, ver: Flandrin \& Montanari 2001 e Santos 2007.

19 Santos 2007: 12.

20 Moreira 2010: 25.

21 Rodrigues 2007: 73.
} 


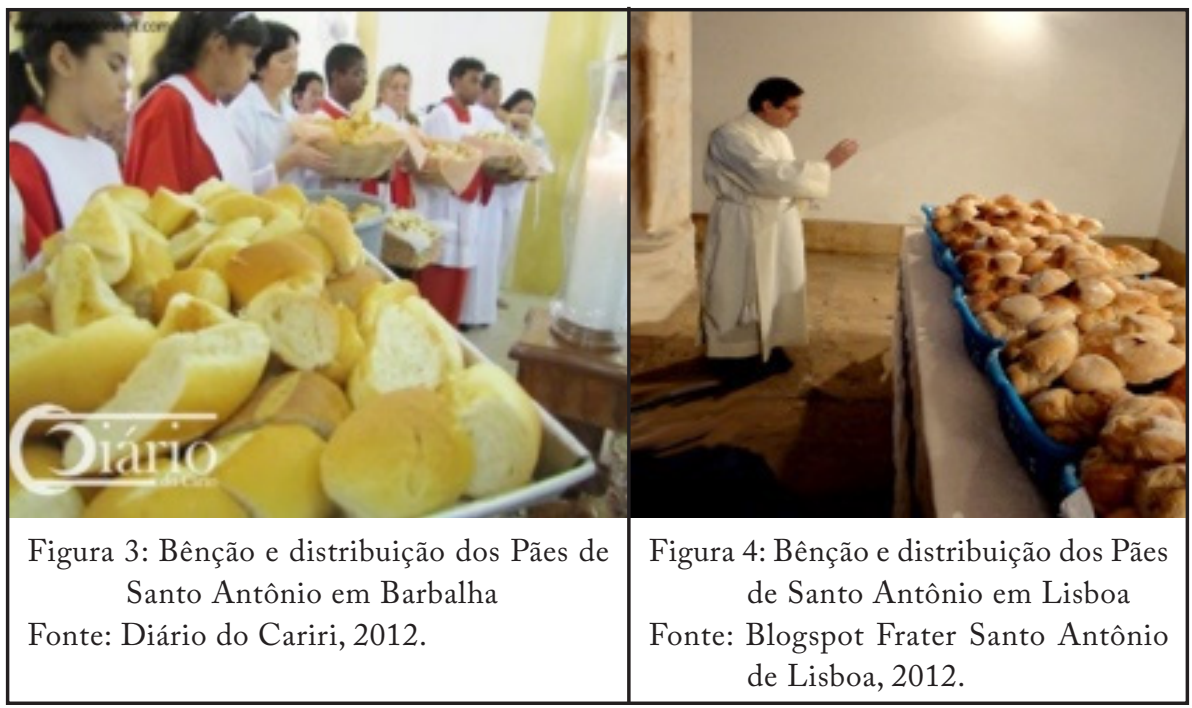

As imagens retratam momentos da festa nas mencionadas cidades. Assim, a primeira, em Barbalha, ocorre a celebração da data pelo padroeiro na Igreja da Matriz. A ilustração revela o momento da missa em que a acólita (no centro) e os coroinhas (auxiliares litúrgicos) seguram os pães nas cestas para que os alimentos sejam abençoados pelo pároco, e, em seguida, sejam distribuídos aos carentes. Tal gesto representa a partilha e a multiplicação das graças através da simbologia do pão traduzida nas seguintes palavras: "Enquanto comiam, tomou Jesus o pão e, depois de pronunciar a bênção, partiu-o e deu-o aos seus discípulos, dizendo: - Tomai, comei isto é o meu corpo" (BÍBLIA, Mateus, XXVI, 26-29). Tal gesto tornou-se ritual nas missas e representa a carne (o pão) como memória da doação da vida de Cristo. A Figura 4 ilustra a benção do "pão dos pobres" na Igreja de Santo de Lisboa para que sejam distribuídos posteriormente.

Salientamos que, antes mesmo de o pão ter entrado na história do cristianismo, o seu uso já era comum na Antiga Mesopotâmia, na época de Ur III. Nesse contexto, Santos explica o emprego da palavra "pão":

O termo que se traduz por "pão" (akalu em acádico e NINDA em sumério), base da alimentação mesopotâmica, consumido quotidianamente, servia freqüentemente para designar "alimentação", o verbo akâlu, significava "comer". Outras palavras podem também ser empregadas nesse sentido, como bultu, que se pode traduzir por "subsistência", construído sobre o verbo balâtu, "viver", ou ainda patnu, "o que é comido", do verbo patânu, "jantar", comer uma refeição ${ }^{22}$.

\footnotetext{
${ }^{22}$ Santos 2007: 9.
} 
No entanto, não esquecemos a nobreza do trigo, que confecciona o pão e que conquistou a humanidade desde o "sexto milênio antes de Cristo" ${ }^{23}$, possibilitando a expansão da agricultura e a colheita para a produção do pão e da cerveja, ambos elementos constituintes dos rituais sagrados ${ }^{24}$.

$\mathrm{Na}$ comensalidade dessa festividade está a bênção com a distribuição dos pães e do vinho, os quais provocam o chamamento para se compartilhar os relacionamentos na promoção da caridade, solidariedade e sociabilidade, pois comer e beber com o outro é criar laços sociais. Por esse ângulo, a comida e a bebida sagrada revelam a institucionalização do ritual religioso, em que o lazer promovido pela comida da festa institui a sociabilidade entre os participantes.

Os laços de afinidade entre as duas cidades aqui abordadas estendem-se às festas populares, bem como à convergência do calendário junino, que, em ambos os países, embalam debates sobre a folclorização e a invenção das tradições. Vejamos, em linhas gerais, a descrição das festas em Barbalha e na capital portuguesa.

De antemão, cabe mencionar que as duas cidades são enfeitadas para promover a festa. Em Barbalha, arranjos com bandeirinhas e flores de papel coloridos embelezam a cidade, como também as imagens e as estátuas do santo antoniano multiplicam-se nas principais vias. Em Lisboa, as ruas são enfeitadas com grinaldas e globos coloridos, juntamente aos cravos de papel.

A fama do santo casamenteiro propicia práticas que aproximam os dois países. Em Barbalha, próximo à Igreja da Matriz, é realizada a "Noite das Solteironas”, ambiente propício para encomendar um noivo ao santo e beber o chá das lascas do Pau da Bandeira de Santo Antônio, pois, segundo reza a tradição, "desencalha" mulheres (além de homens). Tais simpatias são reforçadas no dia 12 , o dia dos namorados no Brasil. O ambiente é alegre, cheio de brincadeiras e simpatias, com a participação de pessoas de todas as gerações.

$\mathrm{Na}$ capital portuguesa, manjericos enfeitados por um cravo de papel com uma quadra de amor são oferecidos às namoradas e ao santo, como, por exemplo, "Santo António, Santo António/ Que bonito que tu és/ Vou buscar um manjerico/ Para o colocar aos teus pés”. Outra prática dedicada ao santo casamenteiro são os "Casamentos de Santo Antônio", realizados desde a década de 1950, com a celebração do matrimônio de vários casais no dia consagrado ao santo.

Em Barbalha, a festa remonta a datas longínquas, como já apresentamos anteriormente, e tem passado por mudanças como a ocorrida no ano de 1928,

\footnotetext{
${ }^{23}$ Fernández-Armesto 2004: 151.

${ }^{24}$ Fernández-Armesto 2004.
} 
quando foi incorporado o cortejo do mastro da bandeira de Santo Antônio ${ }^{25}$. Eis a descrição de tal momento na voz de Luiz Gonzaga e nos versos de Alcymar Monteiro e João Paulo, na música "Festa de Santo Antônio":

A festa de Santo Antônio/ Em Barbalha é de primeira/ A cidade toda corre/ Prá ver o pau da bandeira/ Olha quanta alegria, que beleza/ A multidão faz fileira, hoje é dia/ Vamos buscar o pau da bandeira/ Todo mundo vai a pé/ A cachaça na carroça/ Só num bebe quem num quer/ Só se ouve o comentário/ Lá na igreja do Rosário/ Que a moça pra ser feliz/ Reza-se lá na matriz/ Meu Santo Antônio casamenteiro/ Meu padroeiro, esperei o ano inteiro ${ }^{26}$.

No decorrer dos anos, outras modificações ocorreram, como, por exemplo, em 1973, quando foi adicionado o desfile dos grupos tradicionais, que, aos poucos, teve a participação de associações culturais e artísticas formadas pelas quadrilhas, repentistas ${ }^{27}$, vaqueiros, danças de capoeira, como o maculelê e o pau de fitas, lapinhas ${ }^{28}$, reisados $^{29}$, benditos $^{30}$, penitentes ${ }^{31}$ e zabumbeiros ${ }^{32}$.

Em 1992, devido ao grande número de turistas e de participantes da região, foi implantado um espaço de diversão para a realização de grandes espetáculos no Parque de Eventos Tasso Jereissati. O artesanato local, as bebidas e as comidas tradicionais, cuja predominância é do milho e seus derivados, como o mungunzá, passaram a ser destacados no âmbito da cultura popular e a compor a festa. É nesse sentido que Souza explica o processo

${ }^{25}$ Trata-se do cortejo do pau em que a bandeira de Santo Antônio ficará hasteada todo o ano em frente à Igreja da Matriz. A festa inicia-se com o transporte de um mastro que é extraído de uma árvore distante $6 \mathrm{~km}$ : sai do Sítio São Joaquim e vai até o centro da cidade. Devido ao peso do mastro, o transporte é feito por homens que o carregam nos ombros, os quais são motivados pela cachaça do vigário.

${ }^{26}$ Gonzaga 1987.

${ }^{27}$ São cantadores de viola que rimam os versos e desafiam seus parceiros para improvisarem seus cantos.

28 Presépio que se edifica na época do Natal.

${ }^{29}$ Festa popular que se realiza na véspera do Dia de Reis.

30 Oração entoada de tradição oral.

31 "Os penitentes são remanescentes de uma das maiores secas ocorridas no ano de 1868, em que epidemias se alastraram pelo interior cearense, entre elas, a cólera. Através das penitências com autoflagelação, algumas pessoas conseguiriam se isentar das moléstias que mataram milhares de nordestinos. A prática se espalhou na busca da remissão dos pecados e até hoje os grupos de Penitentes do Nordeste, formados por homens e mulheres, entoam cânticos rezando pelas almas dos mortos, fazendo orações, além de, durante o ato de penitência, se martirizarem com chicotes a fim de reduzir os pecados”. Revista Mostra Cariri 2012, n. 3.

32 Souza explica que: "Banda Cabaçal, Zabumba, Banda de Couro ou Banda de Pífano é um conjunto instrumental de percussão e sopor constituído por um zabumba, bombo ou tambor de couro, uma caixa, também de couro e dois pifes de taboca, soprados vertical ou horizontalmente. [...] Sua origem remonta ao período colonial e resulta da influência das culturas do colonizador, indígena e africana”. Souza 2003: 7. 
de folclorização da festa, por consistir "[...] na transformação da festa num evento cultural e folclórico com a finalidade de desenvolver as potencialidades turísticas do município" 33 .

$\mathrm{Na}$ capital portuguesa, o mês junino é dedicado às festas da cidade, e isso inclui as homenagens a Santo Antônio no dia 13 de junho, com o desfile das marchas populares na Avenida da Liberdade, palco de grandes acontecimentos políticos, artísticos e culturais em Lisboa.

As marchas populares são formadas por associações recreativas e culturais de diferentes bairros da cidade, as quais apresentam nos cortejos um enredo tradicional estampado nas músicas, nas danças coreografadas e nas roupas estilizadas. Sua origem é associada ao Estado Novo (1933-1974), mais precisamente em 1932, quando Antônio de Oliveira Salazar ocupava a chefia do governo. A respeito dessa "invenção", Gonçalves menciona:

A problematização subjacente coloca em xeque o seu caráter "tradicional" que as caracteriza como "produções genuinamente populares". Em um nível, a tradição teria sido forjada a uma realidade patrimonial da cultura popular de Lisboa vinculada à propaganda do regime salazarista, reservando-lhe uma conotação mais conservadora e submetida às "normas" do poder público. Em outro nível, teria sido uma invenção que recuperou antigos folguedos populares dos santos de junho, os combinando com influências das cegadas carnavalescas, dos arraiais, da animação dos mercados públicos, das marches aux flambeaux e do teatro de revista [...]. Por fim, a tradição teria sido inventada por um indivíduo, o Leitão de Barros, e não pela espontaneidade de fundo coletivo. Os modos mais familiares de organização, aliados ao fato das marchas não terem sido plenamente integradas a uma indústria cultural, fizeram com que fossem incluídas muitas vezes no domínio do "folclore" ou da "tradição". Tal conotação, atualizada, ano a ano pela performance dos casais marchantes "tipicamente" trajados, permite uma nova aproximação ao complexo campo da cultura popular ${ }^{34}$.

Para além da invenção do folclore ${ }^{35}$ e das tradições, não se pode negar as aproximações entre as festas lusitanas e as brasileiras, em que as rupturas ocorrem devido às experiências diárias de cada local.

Nas festas populares de ambos os países, a comida e a bebida propiciam o encontro com o outro e com a cultura. Em uma e outra festa, a comida e a bebida são componentes de identidade/diferença própria de cada local/ país/território em seus momentos de lazer e de socialização, por comporem as preferências e oportunidades. Realçamos aqui, entre outras presenças

\footnotetext{
33 Souza 2003: 3.

34 Gonçalves 2013: 30-31.

35 Sobre o folclore brasileiro, consultar, Cascudo s/d.
} 
alimentares, o mungunzá e a cachaça em Barbalha e a sardinha e a sangria em Lisboa.

Sobre o milho, salientamos que é um cereal apreciado em muitos países, entre eles o Brasil. De origem mexicana, a palavra significa "sustento da vida" 36 . Para Fernández-Armesto, o milho é "[...] um vencedor, mais 'ecologicamente tolerante' que qualquer outro dos grandes cereais que se espalharam pelo mundo" ${ }^{37}$. Destacamos que, depois da mandioca, o milho, ao lado do feijão, está presente na raiz alimentar brasileira.

$\mathrm{Na}$ base alimentar do Brasil e, em particular, do nordeste cearense, o cereal tem presença garantida. Contudo, durante as festas juninas, o milho e seus derivados ganham um sentido especial pelo aspecto cultural, simbólico (representação da boa colheita e, consequentemente, fartura à mesa), econômico e pela variedade de receitas com esse importante ingrediente, a exemplo do mungunzá, que predomina na festa de Santo Antônio, o qual é conhecido por seu forte valor nutritivo advindo da união com o feijão.

A receita de um mungunzá é fácil e barata, se considerarmos que caldeirões são feitos para uma grande quantidade de pessoas. Eis a receita: cozinhar o milho e acrescentar o toucinho, mocotó, orelha de porco, feijão e verduras. Há uma grande semelhança desse prato com a cachupa, prato típico de Cabo Verde ${ }^{38}$; daí que se especule que o mungunzá tenha se originado no Brasil em decorrência do povo africano que se estabeleceu em terras brasileiras.

Entre tantas bebidas consumidas na festa, a cachaça é o destaque. Sua presença permeia toda a cerimônia festiva, mas o momento central está em sua apresentação na carroça do vigário e dos transportadores do pau da bandeira. Sobre o carregamento do mastro, Ribeiro, Cunha e Aragão explicam:

Uma técnica de carregamento do pau foi desenvolvida pelos próprios carregadores, de forma que todos juntos erguem o pau até a altura dos ombros, enquanto alguns seguram a ponta com cordas e cabos de aço, freando a velocidade da caminhada por conta do peso. Andam ao passo de cerca cinco metros até a queda do pau no chão sobre pneus colocados por outros fiéis. Os carregadores dizem que todos sentem a hora de derrubar o pau, essa sintonia se dá pela fé e a confiança entre eles. $\mathrm{E}$ assim fazem o percurso de $6 \mathrm{~km}$ até a exaustão de seus corpos, mas a purificação da alma pela promessa paga ${ }^{39}$.

\footnotetext{
36 Embrapa 2008.

37 Fernández-Armesto 2004: 150.

38 Gondim Neto 2012.

39 Ribeiro, Cunha \& Aragão 2009: 5.
} 
Eis uma ilustração do Cortejo do Pau da Bandeira de Santo Antônio:

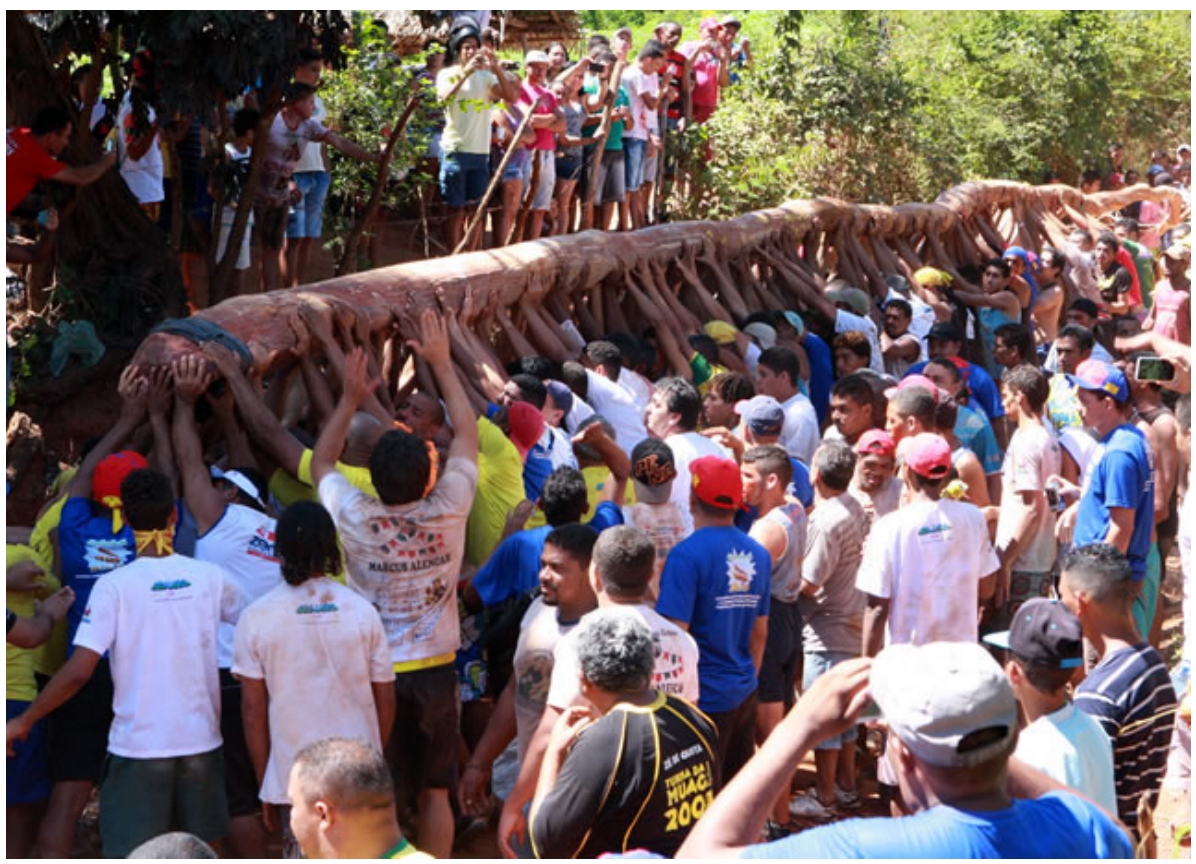

Figura 5: Carregadores e o Cortejo da Bandeira de Santo Antônio em Barbalha Fonte: Diário do Nordeste, 2015.

A figura retrata uma parte do trajeto dos transportadores do pau da bandeira, também chamados de "carregadores do mastro", o qual varia a sua constituição a cada ano, mas geralmente se trata de um tronco de uma árvore oleosa com 22-26 metros, de aproximadamente duas toneladas e 95 centímetros de diâmetro, sendo conduzido por 50 portadores oficiais e mais 200 voluntários que se revezam.

A cachaça está associada ao poderio econômico que teve o nordeste brasileiro com o apogeu do açúcar e seus derivados na região. E Barbalha teve a época áurea dos engenhos de cana de açúcar, com a produção da bebida nos alambiques locais. Para além do uso à mesa, a cachaça era utilizada também com fins medicinais, como, por exemplo, em casos de gripes, picadas de cobras e ferrões de abelhas. Hoje, dos "engenhos agonizam no Cariri" ${ }^{40}$, poucos sobrevivem com a produção da cachaça e da rapadura.

${ }^{40}$ Diário do Nordeste 2008. 
$\mathrm{Na}$ cidade lisboeta, reina a sardinha, que, apesar dos últimos anos, tem diminuído com a pesca na costa portuguesa: "O povo português consome 13 sardinhas por segundo em junho" ${ }^{41}$. Desse período, a sardinha grelhada é muito apreciada nas festas dos santos populares e mantém fortes laços com a identidade cultural do país.

No passado, diante dos rígidos preceitos religiosos de jejuns, abstinência e escassez, era à sardinha que a camada popular recorria para compensar o consumo proteico. Por esse motivo, tal pescado passou, então, a ser considerado o "alimento dos pobres" 42 . Associado a essa camada social, esse peixe foi considerado menos nobre do que a lampreia, o linguado e o salmão. Contudo, encontramos registro do peixe no primeiro livro de cozinha publicado em Portugal, em 1693, intitulado Arte de cozinha ${ }^{43}$, como também na culinária tradicional portuguesa ${ }^{44}$, além da participação na história econômica e industrial portuguesa no desenvolvimento da conserva da sardinha.

Já a bebida consumida nas festas de Lisboa é preferencialmente o vinho, que está presente na história da humanidade e da medicina. Em Portugal, a bebida é fermentada a partir das uvas frescas provindas de muitas regiões. Quente, gelado, tinto, verde, rosé ou branco, o vinho está presente na convivialidade e na tradição portuguesa, proporcionando prazer e a sociabilidade na festa junina, apesar de que, nas últimas décadas, a sangria tem dividido opiniões e gostos. Tal bebida, provavelmente de origem espanhola, tem o nome associado ao derramamento de sangue nas touradas ou da antiga prática médica; contudo, frisamos que, na base dessa bebid,a está o vinho enfraquecido com água, além da adição de frutas, sucos, especiarias (canela) e gelo.

Ao lado das comidas e bebidas conhecidas como tradicionais, há outras que dividem os espaços da festa e proporcionam o mesmo prazer para aqueles que procuram interagir e compartilhar a satisfação da sociabilidade em dias festivos.

\section{Considerações finais}

Este inacabado trabalho revela o enlaçamento da religião com as raízes alimentares. Seja nos momentos sagrados ou nos profanos, a comida e a bebida da festa de Santo Antônio guardam aproximações e distanciamentos do lazer e da sociabilidade, bem como da identidade luso-brasileira.

Assim, nas homenagens ao padroeiro de Barbalha e de Lisboa realizadas no mês junino, as festas tradicionais revelam as aproximações, tais como a

\footnotetext{
${ }^{41}$ Garcia 2015: 1.

42 Braga 2010.

43 Rodrigues 2001.

${ }^{44}$ Modesto 2012.
} 
proteção do santo, a liturgia, a ornamentação, a comida, a bebida e o bem-estar, e os distanciamentos, tais como as particularidades culturais e as condições climáticas, geográficas e econômicas de cada país.

Destacamos ainda a visibilidade da manifestação popular na criação do patrimônio imaterial, que, através da comida e da bebida desse festejo, acopla a formação alimentar na identidade cultural do local, a exemplo das sardinhas e da sangria em Lisboa e do milho (mungunzá) e da cachaça em Barbalha, no Ceará.

\section{REFERÊNCIAS}

\section{Estudos}

Araújo, L. S. (2011), Cultura e lazer na festa de Santo Antônio de Barbalha-CE, Monografia, Curso de Educação Física, Cariri, URCA.

Braga, I. M. R. M. D. (2010), Sabores do Brasil em Portugal: descobrir e transformar novos alimentos (séculos XVI-XX), Senac, São Paulo.

Braga, S. I. G. (2010), "Santo Antônio de Lisboa (Portugal) e de Borba (Amazonas): entre o rito e o teatro em espaços públicos", in Congresso Luso-Afro-Brasileiro de Ciências Sociais, 11, UFBA, Salvador, 1-12.

Cascudo, L. C. (S/D). Dicionário do Folclore Brasileiro, Ediouro Publicações S. A., Rio de Janeiro.

De Varazze, J. (2003), Legenda áurea: vidas de santos, Companhia das Letras, São Paulo.

Del Priore, M. (2000), Festas e utopias no Brasil Colonial, Brasiliense, São Paulo.

Elias, N., Dunning, E. (1992), A busca da excitação, Difel, Lisboa.

Fernández-Armesto, F. (2004), Comida: uma história, Record, Rio de Janeiro.

Figueiredo Filho, J. (2010), Engenhos de rapadura do Cariri: documentário da vida rural, Secult Fortaleza, URCA, Cariri.

Flandrin, J.-L., Montanari, M. (2001), História da alimentação: dos primórdios à Idade Média. Terramar, Lisboa.

Franciscanos de Quaracchi (2012), Livro dos Milagres ou "Florinhas de Santo Antônio de Pádua, Introdução e traduzido por Frei Fernando Félix Lopes, Disponível em: <http://fratersantoantoniodelisboa.blogspot.com.br/2012/02/o-pao-dospobres-de-santo-antonio.html>, Acesso em: 20 ago. 2015.

Gonçalves, R. S. (2013), “O cortejo festivo e sensibilidades urbanas: as marchas populares em Lisboa”, Revista Teoria e Cultura 8.1: 29-38.

Gondim Neto, L. (2012), Alunos de Guiné Bissau, São Tomé e Príncipe e Cabo Verde na Universidade Federal do Ceará-UFC: relações culturais, alimentares e curriculares, Dissertação de Mestrado em Educação Brasileira, UFC, Fortaleza.

Heck, M. C. (2004), “Comer como atividade de lazer”, Estudos Históricos 33: 136-146. 
Jancsó, I., Kantor Í. (orgs.) (2001), Festa: cultura e sociabilidade na América Portuguesa, Imprensa Oficial, Hucitec, Edusp, Papesp, São Paulo.

Lopes, F. F. (1992, 6. ${ }^{\mathrm{a}}$ ed.), Santo Antônio de Lisboa: Doutor Evangélico, Franciscana, Braga.

Modesto, M. L. (2012), Cozinha tradicional portuguesa, Babel, Lisboa.

Montanari, M. (2008), Comida como cultura, Senac, São Paulo.

Monteiro, F. G. (2012), “O pão dos pobres de Santo António”, in Irmã Franciscana da OFS Santo António de Lisboa à Sé, Santo António de Lisboa, Disponível em: $<$ fratersantoantoniodelisboa.blogspot.com.br/2012/02/o-pao-dos-pobres-desanto-antonio.html>, Acesso em: 24 out. 2015.

Moreira, S. A. (2010), "Alimentação e comensalidade: aspectos históricos e antropológicos”, Ciência e Cultura, 62.4: 23-26.

Mott, L. (1997), "Cotidiano e vivência religiosa: entre a capela e o Calundu”, in F. Novais et al. A história da vida privada no Brasil, Companhia das Letras, São Paulo, 155220.

Oliveira, A. J. M. (2011), “Corpo e santidade na América Portuguesa,” in M. Del Priore, M. Amantino (org.), História do corpo no Brasil, Unesp, São Paulo, 45-68.

Peres, E. (2010), Festa brasileira: folias, romarias e congadas, Senac, Imprensa Oficial do Estado de São Paulo, São Paulo.

Pollan, M. (2014), Cozinhar: uma história natural da transformação, Intrínseca, Rio de Janeiro.

Ribeiro, I. L. L., Cunha, N. C., Aragão, R. A. (2009), "Pau da Bandeira”, in IX ENPPG, IX ENICIT e III SIMPIT, Fortaleza, Ceará.

Rodrigues, C. D. (2007), "Do pão e do vinho: esboço de dois víveres no Portugal da Baixa Idade Média”, in Turres Veteras IX, História da alimentação, Colibri, Lisboa, 73-84.

Rodrigues, D. (2001), Arte de cozinha, Colares, Sintra.

Santos, A. R. (2007), "Os alimentos e a mesa na Antiga Mesopotâmia: história da alimentação”, in Turres Veteras IX, História da alimentação, Colibri, Lisboa, 9-17.

Santos, M. P., Duarte, T. M. (2010), “A escrita hagiográfica medieval e a formação da memória dos santos e santas católicos”, in Fazendo Gênero:Diásporas, diversidades, deslocamentos, 9. Santa Catarina, 1-9.

Silva, C. A.T. (2012), "Santo Antônio de Lisboa: a construção da santidade e suas fontes hagiográficas”, in Encontro Regional de História - ANPUH-Rio, UERJ, São Gonçalo, 1-9.

Souza, O. T. (2003), "A Festa do Pau da Bandeira de Santo Antônio de Barbalha (CE): uma experiência religiosa popular," in Simpósio Nacional de História, Anpuh, João Pessoa.

Vieira, P. A. (2012), Essencial Padre Antônio Vieira, Companhia das Letras, São Paulo. 


\section{Fontes}

Bíblia (1966). "Mateus XXVI, 26-29", in Bíblia sagrada: contendo o antigo e o novo testamento, Tradução de João Ferreira de Almeida, Sociedade Bíblica do Brasil, Rio de Janeiro.

Blogcariri (2014), Ornamentação em Barbalha, Cariri, Disponível em: <http://www. blogcariri.com.br/2014/05/barbalha-ce-festa-do-pau-da-bandeira.html>, Acesso em: 26 mai. 2015.

Blogspot Frater (2012), Santo Antônio de Lisboa, Lisboa, Disponível em: <http://frate rsantoantoniodelisboa/2012/02/o-pao-dos-pobres-de-santo-antonio.html>, Acesso em: 26 mai. 2015.

Blogspot Lumeear (2013), Festas populares em Lisboa, Lisboa, Disponível em: <http:// lumeear.blogspot.com.br/2013_06_09_archive.html>, Acesso em: 26 mai. 2015.

Campos, N. (2012), O pão dos pobres de Santo Antônio, Igreja de Santo Antônio de Lisboa à Sé, Disponível em: <http://www.vagalume.com.br/luiz-gonzaga/festa-desanto-antonio.html\#ixzz3hgo9YGG7>, Acesso em: 26 mai. 2015.

Diário do Cariri (2012), "Barbalha-CE: Hoje é dia de Santo Antônio - distribuição de pães representa partilha", Disponível em: <http://www.diariodocariri. com/noticias/ barbalha/30399/barbalha-ce-hoje-e-dia-de-santo-antoniodistribuicao-de-paes-representa-partilha.html>, Acesso em: 31 ago. 2015.

Diário do Cariri (2012), "Bênção e distribuição dos Pães de Santo Antônio em Barbalha", Disponível em: <http://www.diariodocariri.com/noticias/barbalha/30399/ barbalha-ce-hoje-e-dia-de-santo-antonio-distribuicao-de-paes-representapartilha.html>, Acesso em: 26 mai. 2015.

Diário do Nordeste (2008), "Engenhos agonizam no Cariri", Disponível em: <http:// diariodonordeste.verdesmares.com.br/cadernos/regional/engenhos-agonizamno-cariri-1.290417>, Acesso em: 20 set. 2015.

Diário do Nordeste (2012), "Tombamento da Festa de Santo Antônio tem relatório concluído", Disponível em: <http://diariodonordeste.verdesmares.com.br/ cadernos/regional/ tombamento-da-festa-de-santo-antonio-tem-relatorioconcluido-1.110221>, Acesso em: 18 ago. 2015.

Diário do Nordeste (2015), "Ministério Público propõe mudanças no Cortejo do Pau da Bandeira de Santo Antônio", Disponível em: <http://blogs.diariodonordeste. com.br/robertomoreira/ministerio-publico-propoe-mudancas-no-cortejo-dopau-da-bandeira-de-santo-antonio>, Acesso em: 18 ago. 2015.

Emprapa (2008), "Milho e Sorgo", Jornal Eletrônico da Embrapa Milho e Sorgo, Sete Lagoas, 2.7.

Garcia, R. (2015), "Portugal consome 13 sardinhas por segundo em Junho", Público Comunicação Social, publicado em 31 maio 2015, Disponível em: <http://www. 
publico.pt/sociedade/noticia/portugal-consome-13-sardinhas-por-segundoem-junho-1697285>, Acesso em: 26 mai. 2015.

Gonzaga, L. (1987), Festa de Santo Antônio, Composição de Alcymar Monteiro e João Paulo, Disponível em: <http://www.vagalume.com.br/luiz-gonzaga/festa-desanto-antonio.html>, Acesso em: 26 mai. 2015.

IBGE (2014), "Diretoria de Pesquisas, Coordenação de População e Indicadores Sociais, Nota 1: Estimativas da população residente com data de referência $1^{\circ}$ de julho de 2014", Diário Oficial da União, Brasília.

Província Franciscana da Imaculada Conceição do Brasil (2015), Disponível em: <http:// www.franciscanos.org.br>, Acesso em: 26 mai. 2015. 